\title{
Remineralization and fluoride uptake of white spot lesions under dental varnishes
}

Peiyan Shen ${ }^{\mathrm{a}}$, Aidan McKeevera, Glenn D. Walker, ${ }^{\mathrm{a}}$, Yi Yuan ${ }^{\mathrm{a}}$, Coralie Reynoldsa ${ }^{\mathrm{a}}$, James R.

Fernando $^{\mathrm{a}}$, Yu-Yen Chen ${ }^{\mathrm{a}}$, Colin M. MacRae ${ }^{\mathrm{b}}$, Paul Schneider ${ }^{\mathrm{a}}$, Eric C. Reynolds ${ }^{\mathrm{a} *}$

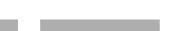

a Oral Health Cooperative Research Centre, Melbourne Dental School, Bio21 Institute, The

University of Melbourne, 720 Swanston Street, Carlton, Melbourne, Victoria 3010, Australia.

bMicrobeam Laboratory, CSIRO Mineral Resources, Clayton, Victoria, Australia

Running title: Enamel remineralization under varnishes

*Corresponding author: Professor Eric Reynolds, Melbourne Dental School, The University

of Melbourne, 720 Swanston Street, Carlton, Melbourne, Victoria, 3010, Australia. Tel +61 3

9341 1547, Email: e.reynolds@unimelb.edu.au

\section{Acknowledgements}

This study is supported by the Australian Government Department of Industry, Innovation and Science Grant ID 20080108.

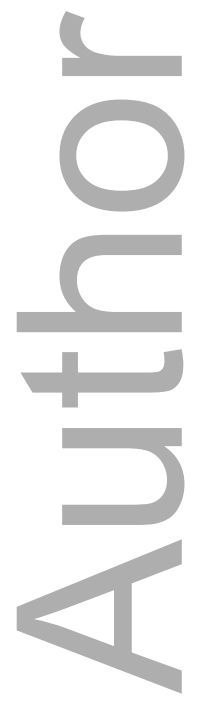

This is the author manuscript accepted for publication and has undergone full peer review but has not been through the copyediting, typesetting, pagination and proofreading process, which may lead to differences between this version and the Version of Record. Please cite this article as doi: $10.1111 /$ ADJ.12787

This article is protected by copyright. All rights reserved 


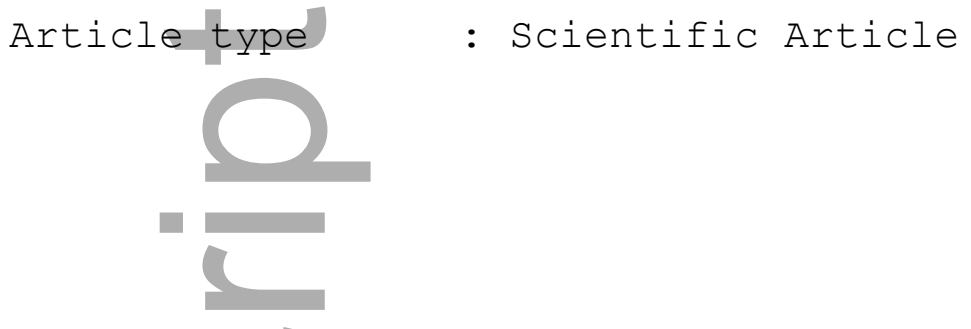

Accepted MS ADJ-06-20-0480

Remineralization and fluoride uptake of white spot lesions under dental varnishes

Peiyan Shen ${ }^{\mathrm{a}}$, Aidan McKeever ${ }^{\mathrm{a}}$, Glenn D. Walker ${ }^{\mathrm{a}}$, Yi Yuan ${ }^{\mathrm{a}}$, Coralie Reynolds ${ }^{\mathrm{a}}$, James R. Fernando $^{\mathrm{a}}$, Yu-Yen Chen ${ }^{\mathrm{a}}$, Colin M. MacRae ${ }^{\mathrm{b}}$, Paul Schneider ${ }^{\mathrm{a}}$, Eric C. Reynolds ${ }^{\mathrm{a} *}$

a Oral Health Cooperative Research Centre, Melbourne Dental School, Bio21 Institute, The University of Melbourne, 720 Swanston Street, Carlton, Melbourne, Victoria 3010, Australia. bMicrobeam Laboratory, CSIRO Mineral Resources, Clayton, Victoria, Australia

Running title: Enamel remineralization under varnishes

*Corresponding author: Professor Eric Reynolds, Melbourne Dental School, The University of Melbourne, 720 Swanston Street, Carlton, Melbourne, Victoria, 3010, Australia. Tel +61 3 9341 1547, Email: e.reynolds@ unimelb.edu.au

\section{Acknowledgements}

This study is supported by the Australian Government Department of Industry, Innovation and Science Grant ID 20080108.

\section{ABSTRACT (200 words)}

Introduction: The aim of this study was to evaluate white spot lesion (WSL) remineralization and fluoride uptake by the application of fluoride varnishes directly onto artificial WSLs in 
vitro.

Methods: MI varnish containing casein phosphopeptide-amorphous calcium phosphate (CPP$\mathrm{ACP}$ ) and 2.26\% fluoride and Duraphat varnish containing 2.26\% fluoride (no added calcium) were compared with a placebo varnish (no added calcium or fluoride). Two WSLs were prepared in enamel slabs and varnish applied to cover one of the two lesions. Each slab was immersed in artificial saliva for 14 days at $37{ }^{\circ} \mathrm{C}$. Mineral content was determined using transverse microradiography and fluoride uptake using electron probe microanalysis. The data were statistically analyzed using a linear mixed model.

Results: Both MI and Duraphat varnishes significantly remineralized the covered and uncovered WSLs when compared with the placebo varnish $(\mathrm{p}<0.001)$. The WSLs covered with varnish exhibited greater remineralization than those uncovered. MI varnish produced the highest level of remineralisation and significantly greater fluoride uptake $(0.44 \pm 0.08$ wt $\%)$ compared with Duraphat $(0.24 \pm 0.03 \mathrm{wt} \%)$ and the placebo varnish $(0.06 \pm 0.05 \mathrm{wt} \%)$.

Conclusion: Varnish containing fluoride and CPP-ACP was superior to varnish containing fluoride alone in promoting WSL remineralization and fluoride uptake.

Key words: Fluoride varnish; MI varnish; CPP-ACP; F uptake; EPMA; enamel subsurface lesion remineralization

\section{INTRODUCTION}

Orthodontic therapy with fixed appliances can result in peribracket white spot lesion formation which can be an aesthetic concern on debanding ${ }^{1}$. The prevalence of peribracket white spot lesion formation during orthodontic therapy has been reported to be as high as $96 \%$ of patients, with labial surfaces of maxillary incisors being the most commonly affected ${ }^{1-4}$. In one recent survey the incidence of patients who developed at least one new white spot lesion during treatment was $72.9 \%{ }^{5}$. The majority of these white spot lesions do not regress while a small proportion (10\%) can actively progress ${ }^{6}$.

Several studies have reported approaches to enhance regression (remineralization) of post-orthodontic white spot lesions with mixed results ${ }^{7-10}$. High concentration $F$ products like dental varnishes are sometimes applied directly to the white spot lesions, however it is unclear whether this promotes subsurface lesion remineralization required for regression to 
translucency or results in only surface precipitation of a fluorhydroxyapatite phase that seals and locks in the subsurface lesion appearance (white spot) by inhibiting ion diffusion into the lesion ${ }^{8,11,12}$.

Recently a dental varnish (MI varnish) containing fluoride (F) and casein phosphopeptide-amorphous calcium phosphate (CPP-ACP) has been commercially released. CPP-ACP which is a saliva biomimetic prevents rapid F precipitation at the surface layer and thereby promotes remineralization deeper in the body of the white spot lesion ${ }^{13,14}$. CPP-ACP has been demonstrated to slow progression of caries and promote remineralization of white spot lesions in several clinical trials ${ }^{7,8,15-17}$. The addition of CPP-ACP to the F varnish may help prevent surface precipitation of fluorhydroxyapatite phases and therefore promote remineralization deep in the body of the white spot lesion to facilitate regression to translucency. The aim of this study was to evaluate remineralization of white spot lesions under dental varnishes in vitro comparing MI varnish containing CPP-ACP with Duraphat varnish. The null hypothesis was that addition of CPP-ACP to a fluoride containing dental varnish has no significant effect on white spot lesion remineralization directly underneath the varnish.

\section{MATERIALS AND METHODS}

\section{Dental varnishes}

Three dental varnishes were selected for analysis (Table 1):1) MI varnish containing casein phosphopeptide amorphous calcium phosphate (CPP-ACP) with $2.26 \%(\mathrm{w} / \mathrm{w})$ fluoride; 2) Duraphat varnish containing 2.26\% (w/w) fluoride (no added calcium); and 3) Placebo varnish (no added calcium or fluoride).

\section{White Spot lesion preparation}

Extracted human third molars were obtained from the staff and students of the University of Melbourne after informed patient consent. The study was approved by the University of Melbourne Human Research Ethics Committee (Approval Number1646366). The teeth were first washed thoroughly in distilled deionized water (DDW) then sterilized by exposure to $10 \%$ neutral buffered formalin solution for two weeks. After sterilization, any soft tissues were removed from the teeth and sound relatively planar buccal and lingual surfaces free of cracking, staining and fluorosis (as viewed under a dissecting microscope) were selected. The outer enamel surfaces were polished wet to a mirror finish using Soflex ${ }^{\mathrm{TM}}$ 
discs on a slow speed contra-angle dental handpiece. Each polished surface was cut from the tooth as an approximately $8 \times 4 \mathrm{~mm}$ slab, using a water-cooled diamond blade saw and the whole slab was then covered with acid-resistant nail varnish except for two (occlusal and gingival) mesiodistal windows (approximately 1 x $8 \mathrm{~mm}$ each) separated from each other by about $1 \mathrm{~mm}$. The slabs were treated to create white spot lesions in the enamel windows by suspending each slab in $40 \mathrm{~mL}$ of unagitated demineralization buffer, consisting of $80 \mathrm{~mL} / \mathrm{L}$ Noverite K-702 polyacrylate solution (Lubrizol Corporation, Wickliffe, OH), $500 \mathrm{mg} / \mathrm{L}$ hydroxyapatite (Bio-Gel® HTP, Bio Rad Laboratories, Richmond CL), and 0.1 mol/L lactic acid (Ajax Chemicals, Auburn NSW) pH 4.8, for 4 days at $37{ }^{\circ} \mathrm{C}^{18}$. A change of solution was made after two days at which time the slabs were removed from the solution, rinsed thrice with DDW, blotted dry and placed into fresh demineralization buffer. The slabs were similarly rinsed with DDW and dried after four days of demineralization. This demineralization procedure produces consistent subsurface lesions $100 \mu \mathrm{m}$ deep with intact surface layers, as evaluated by microradiography of sections of the artificial lesions. After demineralization, the enamel slabs were cut perpendicular to the windows into two $4 \times 4 \mathrm{~mm}$ half-slabs and the cut surface of each half-slab then covered with nail varnish. One of the half-slabs was retained as the demineralization control and stored in a labeled $1.5 \mathrm{~mL}$ sealed microcentrifuge tube together with a drop of DDW, thereby creating a humidified environment. The other half-slab (test half-slab) after application of the dental varnish (Fig 1) was exposed to artificial saliva (AS) to test remineralization (see below).

\section{Remineralization assay and transverse microradiography}

Thirty half-slabs (test half-slab) were randomly divided into three experimental groups $(\mathrm{n}=10)$ :

1) MI varnish containing casein phosphopeptide amorphous calcium phosphate (CPP-ACP) with $2.26 \%(\mathrm{w} / \mathrm{w})$ fluoride; 2) Duraphat varnish containing $2.26 \%$ (w/w) fluoride (no added calcium, positive control); and 3) Placebo varnish as negative control (no added calcium or fluoride). One of the three varnishes (MI varnish, Duraphat varnish, or placebo varnish) was painted over one of the white spot lesions (gingival or occlusal) on the test half-slab (Fig 1). Dental varnish (6 mg) was carefully applied to each experimental half-slab as determined accurately by weighing each half-slab before and after applying the varnish. Each half-slab was coded and then suspended in $5 \mathrm{~mL}$ of unagitated artificial saliva (AS), consisting of 50 $\mathrm{mM} \mathrm{NaCl}, 0.5 \mathrm{mM} \mathrm{CaCl}_{2}$ and $0.5 \mathrm{mM} \mathrm{Na}_{2} \mathrm{HPO}_{4}, \mathrm{pH} 7.0$ and incubated at $37^{\circ} \mathrm{C}$ for two weeks. This treatment was designed to mimic the situation of application of the varnishes to 
white spot lesions post-orthodontic therapy after debanding. After treatment each half-slab was removed from the solution, rinsed thoroughly with deionized water, blotted dry, then paired with its control half-slab.

Each paired test and control half-slabs was placed into freshly poured transparent cold curing methacrylate resin with the lesion windows parallel. The resin vial was marked at the top corner to identify the coded test and control half-slabs and the resin allowed to set at room temperature overnight. Sections approximately $300 \mu \mathrm{m}$ thick were cut from the embedded slabs perpendicular to the lesion surface using an internal annulus saw microtome. The sections were lapped down to $100 \pm 5 \mu \mathrm{m}$ using a RotoPol/RotoForce lapping instrument (Struers, Denmark) with 1200 grit lapping paper. The lapped sections were removed from the lapping instrument with absolute ethanol and rinsed in deionized water, blotted dry and stored on soft tissue between glass slides. Each section, which contained the lesion treated with the coded dental varnish and the demineralized control lesion from the same enamel slab, was radiographed along with an aluminum stepwedge with $7 \times 37.5 \mu \mathrm{m}$ thick increments using Microchrome High Resolution glass plates (3 x 3 x 0.06 in., Microchrome, USA) and copper $\mathrm{K} \alpha$ radiation at $20 \mathrm{kV}, 30 \mathrm{~mA}$ for eight minutes. Each glass plate was developed in Microchrome Developer D5-C for five minutes, placed into glacial acetic acid stop bath for 30 seconds and then fixed in Microchrome Fixer F4-C for five minutes.

Radiographic images of the lesions were viewed via transmitted light through a Leica DM 5500B microscope (Leica, Germany). The images were acquired by a ProgRes ${ }^{\circ}$ MF scan digital camera (Jenoptik, Jena, Germany) under the control of Image-Pro Plus version 7.0 imaging software on a Sci-Tech Imaging Workstation (SciTech, Preston, VIC, Australia). Images of the lesions and the neighbouring areas of sound enamel were scanned by an operator blinded to the varnish code using the program's line luminance function that gives readings in grey values. An area free of artifacts or cracks was selected for analysis. Each scan comprised 200 readings taken from the tooth surface to sound enamel.

The stepwedge image on each slide was scanned and the averaged step grey value readings were plotted against aluminum thickness. The readings for the tooth section images were within the linear portion of the stepwedge curve and linear regression was used to convert the grey value data into values of equivalent thickness of aluminum. The section thickness was measured and the \% mineral data computed using the equation of Angmar et al 19 and the linear absorption coefficients of aluminum, organic matter plus water and apatite mineral $(131.5,11.3$, and 260.5 respectively). The image of the sound enamel was scanned 
six times and averaged to give a control sound-enamel densitometric profile. The lesion images of the dental varnish treated windows and demineralization control windows were similarly scanned and the vol\% mineral content profiles determined. The start and end of the lesion were defined as the points where the mineral density was $20 \%$ and $95 \%$ respectively that of the sound enamel. These measurements were then used to determine lesion depth. The depth of the lesion on the half-slab not exposed to the dental varnish was designated LDc for lesion depth control. That of the lesion on the half-slabs treated with dental varnish was designated LDv for lesion depth varnish. The change in lesion depth caused by the varnish treatment was LDc - LDv.

The $\%$ mineral profile of each enamel slab's demineralized control and dental varnishtreated lesion was compared with the sound enamel \% mineral profile of the same section. The difference between the area under the densitometric profile of the demineralization control lesion and the sound enamel, calculated by trapezoidal integration, was represented by $\Delta \mathrm{Zc}$. The difference between the area under the densitometric profile of the dental varnish-treated lesion and the sound enamel, calculated by trapezoidal integration, was represented by $\Delta \mathrm{Zv}$. These parameters were then used to calculate integrated mineral loss (vol\% mineral. $\mu \mathrm{m}$ ) between the control and varnish-treated enamel $\Delta \mathrm{Zc}-\Delta \mathrm{Zv}$ and $\%$ Remineralization $(\% \mathrm{R}): \frac{\Delta \mathrm{Zc}-\Delta \mathrm{Zv}}{\Delta \mathrm{Zc}} \times 100$

Digital images of varnish samples were taken before and after 14 days exposure to the AS for each of the three treatment groups.

\section{Varnish ions release}

After the remineralization experiment (see above) the AS from each sample was collected. The coded AS samples were analyzed using ion chromatography to determine the levels of calcium, inorganic phosphate and fluoride ions. The ion chromatography system was equipped with cation (IonPac CS12; Dionex, CA, USA) and anion (IonPac AS18; Dionex, CA,USA) columns and two separated conductivity detectors (ICS-3000; Dionex, CA, USA).

\section{Electron Probe Micro-analysis (EPMA)}

The section of enamel used for transverse microradiography (TMR) was embedded in epoxy resin (Epofix; Struers, Denmark) on a 1 inch specimen holder. The resin was flat 
polished to expose the enamel sections using 2,400 grit abrasive paper. To achieve optical smoothness 3 and $1 \mu \mathrm{m}$ diamond polishing pastes were used on a cloth pad with final finishing accomplished with a $0.25 \mu \mathrm{m}$ aluminium oxide paste. All samples and standards were coated with $20 \mathrm{~nm}$ of carbon-by-carbon arc deposition using a Dynavac 300 coater. The operating parameters for EPMA were as described previously ${ }^{20}$.

\section{Statistical analyses}

Differences between mean lesion depth, integrated mineral loss and $\%$ remineralization across the three treatments were measured using a linear mixed model with differences between means measured using pairwise comparisons with a Sidak adjustment for multiple comparisons. Correlation between \% remineralization and $\mathrm{F}$ enamel uptake in wt\% after treatment was measured using Pearson's Product-Moment Correlation Coefficient. For all statistical tests, the significance level was set at $\alpha=0.05$. All statistical analyses were performed using SPSS Version 22 statistical software (IBM Corp. NY, USA).

\section{RESULTS}

\section{White Spot Lesion remineralization}

There was no significant difference in lesion depth (LDc) and mineral loss $(\Delta \mathrm{Zc})$ for the control enamel half-slabs, which were used to pair with their matching half-slab treated with one of the dental varnishes (Table 2). Both fluoride-containing varnishes tested (Duraphat varnish and MI varnish) significantly enhanced lesion remineralization when compared with the placebo varnish (Table 2). The CPP-ACP/F containing varnish (MI varnish) promoted $123 \%$ greater remineralization $(\mathrm{p}<0.001)$ than the fluoride-alone varnish (Duraphat) (Table 2). The superiority of MI varnish was shown both in lesion remineralization and reduction in lesion depth (Table 2).

As shown in Fig. 1, the design of the study involved one of the two test white spot lesions being covered with either Placebo, Duraphat or MI varnish (covered lesion) and the other white spot lesion was left blank (uncovered lesion) when exposed to AS during the study. It was found, as presented in Table 2 that there was no significant difference in remineralization between covered lesions and uncovered lesions when treated with Placebo. However, significant remineralization was observed for the covered lesions either treated by MI varnish or Duraphat varnish $(41.2 \pm 7.8 \%$ and $18.4 \pm 2.3 \%$ respectively), with significantly greater remineralization produced by MI varnish (Table 2). The uncovered 
lesions adjacent to the varnish covered lesions produced approximately half the level of remineralization observed in the covered lesions for both MI varnish $(23.0 \pm 5.6 \%)$ and Duraphat varnish $(9.7 \pm 2.9 \%)$ treatment $(\mathrm{p}<0.001)$.

Representative microradiographic images of the white spot lesions after treatment showed that the fluoride only varnish (Duraphat) reminineralized predominately the surface layer of the lesions whereas MI varnish remineralized throughout the body of the lesion (Fig. 2). This uniform remineralization of the lesions by treatment with MI varnish resulted in $41 \%$ return of the lost mineral to produce a mineral content of around $80 \mathrm{vol} \%$ assuming that sound enamel is on average 90 - 92 vol\% mineral.

\section{Ion release and enamel fluoride uptake}

Analysis of the released calcium, inorganic phosphate and fluoride ion levels in the AS after treatment with the different varnishes using ion chromatography showed significantly higher levels of all ions in the MI varnish treatment group when compared with that in the Duraphat varnish treatment group ( $<$ 0.001) (Table 3). Remineralized white spot lesions under dental varnishes were analyzed for fluoride uptake using EPMA. MI varnish produced significantly greater lesion fluoride uptake $(0.44 \pm 0.08 \mathrm{wt} \%)$ compared with Duraphat $(0.24$ $\pm 0.03 \mathrm{wt} \%)$ and the placebo varnish $(0.06 \pm 0.05 \mathrm{wt} \%)$ (Table 4). The level of fluoride uptake was significantly correlated $(\mathrm{p}<0.0001)$ with the level of remineralization (Table 4). From the data presented in Table 4 it can be seen that MI varnish produced remineralization $55 \%$ greater than the mineral level predicted from the EMPA measured fluoride content. This is consistent with the presence of the CPP-ACP also driving remineralization by providing bioavailable calcium and phosphate ions together with the fluoride ions.

\section{DISCUSSION}

The results of this study demonstrated that MI varnish containing CPP-ACP and F significantly enhanced white spot lesion remineralization when compared with the fluoride alone Duraphat varnish, hence the null hypothesis was rejected.

Duraphat is a commonly used fluoride varnish that has been tested by other authors in similar studies and is well defined in terms of fluoride release and caries prevention ${ }^{21-23}$. The results of this study showed that both MI varnish and Duraphat varnish containing 5\% sodium fluoride $(2.26 \% \mathrm{w} / \mathrm{w}$ fluoride) significantly promoted white spot lesion remineralization of covered lesions by $41 \%$ and $18 \%$, respectively. Considering the importance of fluoride ion release from the varnishes, it is imperative that the addition of 
calcium and phosphate ions does not reduce the bioavailability of the fluoride ions. MI varnish containing CPP-ACP released significantly higher fluoride ion levels than Duraphat as well as higher levels of calcium and phosphate ions, and was superior to Duraphat in promoting enamel subsurface lesion remineralization particularly in the body of the lesion, which is important for the regression of white spots back to translucency. To restore translucency, remineralisation needs to be uniform throughout the lesion to produce an average mineral content of around 80 vol\% mineral or greater. MI varnish also produced greater $\mathrm{F}$ uptake into the enamel which correlated with the higher level of remineralization of the white spot lesions. These data taken together indicate that the F in MI varnish was highly bioavailable even though the varnish also contained CPP-ACP. The combination of CPP$\mathrm{ACP}$ and $\mathrm{F}$ to form CPP-ACFP nanocomplexes has been shown to be superior to $\mathrm{F}$ alone in inhibiting enamel demineralization and promoting remineralization in several in situ and in vivo randomized controlled clinical trials of other oral care products $7,8,14-17,24-35$. Furthermore, CPP-ACP and F promotes more homogeneous remineralization throughout the body of the lesion, which has been attributed to the stabilizing properties of the CPP ${ }^{36}$. Ordinarily, contact between free fluoride, calcium and phosphate ions would lead to rapid precipitation of fluorhydroxyapatite at the enamel surface. In the presence of CPP however, the ions are stabilized as highly bioavailable electroneutral nanoclusters in a fluorapatite-like molar relationship ${ }^{36,37}$. The high release of calcium, phosphate and fluoride ions from MI varnish can be attributed to the presence of these highly bioavailable CPP-ACFP nanocomplexes ${ }^{13,36-40}$. These nanocomplexes have a hydrodynamic radius of $2.12 \pm 0.26 \mathrm{~nm}$ ${ }^{37}$ which allows rapid diffusion out of the varnish and into the enamel subsurface lesion through the intraprismatic spaces ${ }^{36}$. The presence of the CPP-ACFP nanocomplexes helps explain the superior ability of MI varnish in promoting remineralization and F uptake into the body of the white spot lesion. Representative microradiographic images of the white spot lesions after treatment in the current study confirmed that the fluoride-only varnish remineralized predominantly at the surface layer whereas MI varnish containing CPP-ACP remineralized throughout the body of the lesion.

The results of the present study demonstrating superiority of MI varnish over a fluoride-only varnish are consistent with an earlier study by Shen et al ${ }^{13}$ where human enamel slabs were covered with one of six test dental varnishes. The varnish-covered enamel slabs were then individually immersed in a polyacrylate demineralization buffer $\mathrm{pH} 4.8$ for four days at $37^{\circ} \mathrm{C}$ with a change of solution each day. The Shen et al ${ }^{13}$ study demonstrated that while all fluoride-containing varnishes significantly inhibited enamel demineralization 
when compared with the placebo varnish, MI varnish, containing fluoride and CPP-ACP released the highest levels of calcium, phosphate and fluoride ions and was superior to all the other fluoride varnishes in protecting against enamel demineralization ${ }^{13}$. The results of the current study are also in agreement with previous studies suggesting superiority of the MI varnish in terms of very high ion release and protection of enamel demineralization around orthodontic brackets as measured using optical coherence tomography ${ }^{41,42}$.

Tuloglu et $\mathrm{al}^{43}$ also found that fluoride varnish containing CPP-ACP was more effective in increasing the acid resistance of primary enamel during $\mathrm{pH}$ cycling when compared with other fluoride varnishes. Similarly, using in vitro pH cycling methodology Wierichs et al $^{44}$ demonstrated that MI varnish with CPP-ACP was superior to silver diammine fluoride containing 35,000 ppm F, Duraphat and Clinpro varnish in protecting demineralization of dentine. Other studies have also reported superiority of MI varnish over other fluoride-containing varnishes using in vitro erosion/abrasion challenges ${ }^{45,46}$.

In conclusion, the current study demonstrated that dental varnishes applied directly to white spot lesions could promote remineralization in vitro. Furthermore, MI varnish, by releasing more bioavailable calcium, phosphate and fluoride ions was superior to Duraphat containing fluoride alone in promoting $\mathrm{F}$ uptake and in the amount and pattern of remineralization of white spot lesions underneath the varnish with only MI varnish remineralizing the body of the lesion. The results suggest that MI varnish would be the preferred varnish for the treatment of white spot lesions during and after orthodontic treatment due to the superior remineralization in the body of the lesion which would help regress the lesion to translucency.

\section{Conclusion}

Dental varnishes could promote white spot lesion remineralization when applied directly to the lesion. MI varnish containing fluoride and CPP-ACP was superior to Duraphat varnish containing fluoride alone in promoting white spot lesion remineralization and $\mathrm{F}$ uptake. Duraphat remineralized only at the surface whereas MI varnish remineralized throughout the lesion.

\section{REFERENCES}

1. Gorelick L, Geiger AM, Gwinnett AJ. Incidence of white spot formation after bonding 
and banding. Am J Orthod 1982;81:93-98.

2. Geiger AM, Gorelick L, Gwinnett AJ, Griswold PG. The effect of a fluoride program on white spot formation during orthodontic treatment. Am J Orthod Dentofacial Orthop 1988;93:29-37.

3. Mitchell L. Decalcification during orthodontic treatment with fixed appliances-an overview. Br J Orthod 1992;19:199-205.

4. Mizrahi E. Surface distribution of enamel opacities following orthodontic treatment. Am J Orthod 1983;84:323-331.

5. Richter AE, Arruda AO, Peters MC, Sohn W. Incidence of caries lesions among patients treated with comprehensive orthodontics. Am J Orthod Dentofacial Orthop 2011;139:657-664.

6. van der Veen MH, Mattousch T, Boersma JG. Longitudinal development of caries lesions after orthodontic treatment evaluated by quantitative light-induced fluorescence. Am J Orthod Dentofacial Orthop 2007;131:223-228.

7. Andersson A, Skold-Larsson K, Hallgren A, Petersson LG, Twetman S. Effect of a dental cream containing amorphous cream phosphate complexes on white spot lesion regression assessed by laser fluorescence. Oral Health Prev Dent 2007;5:229-233.

8. Bailey DL, Adams GG, Tsao CE, et al. Regression of post-orthodontic lesions by a remineralizing cream. J Dent Res 2009;88:1148-1153.

9. Welbury RR, Carter NE. The hydrochloric acid-pumice micro-abrasion technique in the treatment of post-orthodontic decalcification. Br J Orthod 1993;20:181-185.

10. Willmot DR. White lesions after orthodontic treatment: does low fluoride make a difference? J Orthod 2004;31:235-242.

11. Ogaard B, Rolla G, Arends J, ten Cate JM. Orthodontic appliances and enamel demineralization Part 2. Prevention and treatment of lesions. Am J Orthod Dentofacial Orthop 1988;94:123-128.

12. Retief DH, Bradley EL, Holbrook M, Switzer P. Enamel fluoride uptake, distribution and retention from topical fluoride agents. Caries Res 1983;17:44-51.

13. Shen P, Bagheri R, Walker GD, et al. Effect of calcium phosphate addition to fluoride containing dental varnishes on enamel demineralization. Aust Dent J 2016;61:357-365.

14. Shen P, Walker GD, Yuan Y, et al. Importance of bioavailable calcium in fluoride dentifrices for enamel remineralization. J Dent 2018;78:59-64.

15. Morgan MV, Adams GG, Bailey DL, Tsao CE, Fischman SL, Reynolds EC. The anticariogenic effect of sugar-free gum containing CPP-ACP nanocomplexes on 
approximal caries determined using digital bitewing radiography. Caries Res 2008;42:171-184.

16. Robertson MA, Kau CH, English JD, Lee RP, Powers J, Nguyen JT. MI Paste Plus to prevent demineralization in orthodontic patients: a prospective randomized controlled trial. Am J Orthod Dentofacial Orthop 2011;140:660-668.

17. Sim C, Walker GD, Manton DJ, et al. Anticariogenic efficacy of a saliva biomimetic in head-and-neck cancer patients undergoing radiotherapy. Aust Dent J 2019;64:47-54.

18. White DJ. Use of synthetic-polymer gels for artificial carious lesion preparation. Caries Res 1987;21:228-242.

19. Angmar B, Carlström D, Glas J-E. Studies on the ultrastructure of dental enamel: IV. The mineralization of normal human enamel. J Ultrastruct Res 1963;8:12-23.

20. Cochrane NJ, Iijima Y, Shen P, et al. Comparative study of the measurement of enamel demineralization and remineralization using transverse microradiography and electron probe microanalysis. Microsc Microanal 2014;20:937-945.

21. Shen C, Autio-Gold J. Assessing fluoride concentration uniformity and fluoride release from three varnishes. J Am Dent Assoc 2002;133:176-182.

22. Marinho VC, Higgins JP, Logan S, Sheiham A. Fluoride varnishes for preventing dental caries in children and adolescents. Cochrane Database Syst Rev 2002:CD002279.

23. Castillo JL, Milgrom P, Kharasch E, Izutsu K, Fey M. Evaluation of fluoride release from commercially available fluoride varnishes. J Am Dent Assoc 2001;132:13891392.

24. Reynolds EC, Cai F, Cochrane NJ, et al. Fluoride and casein phosphopeptideamorphous calcium phosphate. J Dent Res 2008;87:344-348.

25. Shen P, Manton DJ, Cochrane NJ, et al. Effect of added calcium phosphate on enamel remineralization by fluoride in a randomized controlled in situ trial. J Dent 2011;39:518-525.

26. Srinivasan N, Kavitha M, Loganathan SC. Comparison of the remineralization potential of CPP-ACP and CPP-ACP with 900 ppm fluoride on eroded human enamel: An in situ study. Arch Oral Biol 2010;55:541-544.

27. Yazicioglu O, Ulukapi H. The investigation of non-invasive techniques for treating early approximal carious lesions: an in vivo study. Int Dent J 2014;64:1-11.

28. Krithikadatta J, Fredrick C, Abarajithan M, Kandaswamy D. Remineralisation of occlusal white spot lesion with a combination of $10 \%$ CPP-ACP and $0.2 \%$ sodium 
fluoride evaluated using Diagnodent: a pilot study. Oral Health Prev Dent 2013;11:191196.

29. Thepyou R, Chanmitkul W, Thanatvarakorn O, et al. Casein phosphopeptideamorphous calcium phosphate and glass ionomer show distinct effects in the remineralization of proximal artificial caries lesion in situ. Dent Mater J 2013;32:648653.

30. Yengopal V, Mickenautsch S. Caries preventive effect of casein phosphopeptideamorphous calcium phosphate (CPP-ACP): a meta-analysis. Acta Odontol Scand 2009;67:321-332.

31. Bader JD. Casein phosphopeptide-amorphous calcium phosphate shows promise for preventing caries. Evid Based Dent 2010;11:11-12.

32. Lopatiene K, Borisovaite M, Lapenaite E. Prevention and Treatment of White Spot Lesions During and After Treatment with Fixed Orthodontic Appliances: a Systematic Literature Review. J Oral Maxillofac Res 2016;7:e1.

33. Tao S, Zhu Y, Yuan H, et al. Efficacy of fluorides and CPP-ACP vs fluorides monotherapy on early caries lesions: A systematic review and meta-analysis. PLoS One 2018;13:e0196660.

34. Bijle MNA, Yiu CKY, Ekambaram M. Calcium-Based Caries Preventive Agents: A Meta-evaluation of Systematic Reviews and Meta-analysis. J Evid Based Dent Pract 2018;18:203-217 e204.

35. Pithon MM, Baiao FS, Sant'Anna LID, Tanaka OM, Cople-Maia L. Effectiveness of casein phosphopeptide-amorphous calcium phosphate-containing products in the prevention and treatment of white spot lesions in orthodontic patients: A systematic review. J Investig Clin Dent 2019;10:e12391.

36. Cochrane NJ, Cai F, Huq NL, Burrow MF, Reynolds EC. New approaches to enhanced remineralization of tooth enamel. J Dent Res 2010;89:1187-1197.

37. Cross KJ, Huq NL, Stanton DP, Sum M, Reynolds EC. NMR studies of a novel calcium, phosphate and fluoride delivery vehicle-alpha(S1)-casein(59-79) by stabilized amorphous calcium fluoride phosphate nanocomplexes. Biomaterials 2004;25:50615069.

38. Cross KJ, Huq NL, Reynolds EC. Casein phosphopeptides in oral health - Chemistry and clinical applications. Curr Pharm Des 2007;13:793-800.

39. Cochrane NJ, Saranathan S, Cai F, Cross KJ, Reynolds EC. Enamel subsurface lesion remineralisation with casein phosphopeptide stabilised solutions of calcium, phosphate 
and fluoride. Caries Res 2008;42:88-97.

40. Cochrane NJ, Reynolds EC. Calcium phosphopeptides -- mechanisms of action and evidence for clinical efficacy. Adv Dent Res 2012;24:41-47.

41. Pithon MM, dos Santos MJ, Andrade CSS, et al. Effectiveness of varnish with CPPACP in prevention of caries lesions around orthodontic brackets: an OCT evaluation. Eur J Orthod 2015;37:177-182.

42. Cochrane NJ, Shen P, Yuan Y, Reynolds EC. Ion release from calcium and fluoride containing dental varnishes. Aust Dent J 2014;59:100-105.

43. Tuloglu N, Bayrak S, Tunc ES, Ozer F. Effect of fluoride varnish with added casein phosphopeptide-amorphous calcium phosphate on the acid resistance of the primary enamel. BMC Oral Health 2016;16:103.

44. Wierichs RJ, Stausberg S, Lausch J, Meyer-Lueckel H, Esteves-Oliveira M. CariesPreventive Effect of $\mathrm{NaF}, \mathrm{NaF}$ plus TCP, NaF plus CPP-ACP, and SDF Varnishes on Sound Dentin and Artificial Dentin Caries in vitro. Caries Res 2018;52:199-211.

45. Bayrak S, Tuloglu N, Bicer H, Sen Tunc E. Effect of Fluoride Varnish Containing CPP-ACP on Preventing Enamel Erosion. Scanning 2017;2017:1897825.

46. Alexandria AK, Vieira TI, Pithon MM, et al. In vitro enamel erosion and abrasioninhibiting effect of different fluoride varnishes. Arch Oral Biol 2017;77:39-43.

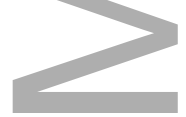

\section{Figure Legends}

Fig. 1. Diagram of how enamel samples were prepared and treated with dental varnish. One white spot lesion of the test half-slab (left) was painted with dental varnish (MI varnish, Duraphat or Placebo varnish) and the other white spot lesion of the test half-slab (left) was left exposed. The right half-slab was used as control (see method).

Fig. 2. Representative TMR images for dental varnish treated lesions with ruler bar of $50 \mu \mathrm{m}$ shown under the lesion.

Table 1. Dental varnishes selected for analysis. 


\begin{tabular}{|l|l|l|l|}
\hline Product & Manufacturer & Batch No. & \multicolumn{1}{|c|}{ Composition (w/w) from MSDS ${ }^{\dagger}$} \\
\hline $\begin{array}{l}\text { Placebo } \\
\text { Varnish }\end{array}$ & $\begin{array}{l}\text { GC, Tokyo, } \\
\text { Japan }\end{array}$ & 1311251 & $\begin{array}{l}30-50 \% \text { polyvinyl acetate, 10-30\% } \\
\text { hydrogenated rosin, 20-30\% ethanol, } \\
1-5 \% \text { silicon dioxide }\end{array}$ \\
\hline Duraphat & $\begin{array}{l}\text { Colgate Oral } \\
\text { Care, Sydney, }\end{array}$ & 174197 & $\begin{array}{l}30-60 \% \text { colophonium, 10-30\% } \\
\text { ethanol, 5\% sodium fluoride, other } \\
\text { ingredients }\end{array}$ \\
\hline MI Varnish & GC, Tokyo, & 1412172 & $\begin{array}{l}30-50 \% \text { polyvinyl acetate, 10-30\% } \\
\text { hydrogenated rosin, 20-30\% ethanol, } \\
5 \% \text { sodium fluoride, 5\% CPP-ACP, } \\
1-5 \% \text { silicon dioxide }\end{array}$ \\
\hline
\end{tabular}

${ }^{\dagger} \mathrm{MSDS}=$ material safety data sheet.

Table 2. Remineralization parameters for lesions covered by placebo, Duraphat and MI varnish and for lesions uncovered but adjacent to the varnish.

\begin{tabular}{|c|c|c|c|c|c|}
\hline Treatment & $\begin{array}{l}\text { LDc } \\
(\mu \mathrm{m})\end{array}$ & $\begin{array}{c}\text { LDc-LDv } \\
(\mu \mathrm{m})\end{array}$ & $\begin{array}{l}\Delta \mathbf{Z c} \\
(\mu \mathrm{m})\end{array}$ & $\begin{array}{c}\Delta \mathbf{Z c}-\Delta \mathbf{Z v} \\
(\operatorname{vol} \% \min . \mu \mathrm{m})\end{array}$ & $\% \mathrm{R}$ \\
\hline $\begin{array}{l}\text { Placebo } \\
\text { Covered }\end{array}$ & $93.4 \pm 6.8$ & $-5.1 \pm 9.6$ & $2302 \pm 448$ & $57.9 \pm 34.6$ & $2.8 \pm 2.1$ \\
\hline $\begin{array}{l}\text { Placebo } \\
\text { Uncovered }\end{array}$ & $93.3 \pm 9.2$ & $-2.5 \pm 10.4$ & $2246 \pm 495$ & $72.6 \pm 62.4$ & $3.1 \pm 2.6$ \\
\hline $\begin{array}{l}\text { Duraphat } \\
\text { Covered }\end{array}$ & $90.1 \pm 6.3$ & $5.4 \pm 5.9$ & $2080 \pm 375$ & $386.9 \pm 97.9^{\S}$ & $18.4 \pm 2.3^{\S}$ \\
\hline $\begin{array}{l}\text { Duraphat } \\
\text { Uncovered }\end{array}$ & $97.2 \pm 9.5$ & $7.3 \pm 9.3$ & $2237 \pm 460$ & $221.1 \pm 85.3^{\mathbb{T}}$ & $9.7 \pm 2.9^{\mathbb{T l}}$ \\
\hline MI Covered & $95.6 \pm 4.9$ & $25.3 \pm 9.9^{\dagger}$ & $2288 \pm 377$ & $943.7 \pm 231.5^{\dagger}$ & $41.2 \pm 7.8^{\dagger}$ \\
\hline $\begin{array}{l}\text { MI } \\
\text { Uncovered }\end{array}$ & $94.9 \pm 10.5$ & $12.6 \pm 10.7^{\ddagger}$ & $2436 \pm 576$ & $569.2 \pm 219.8^{\ddagger}$ & $23.0 \pm 5.6^{+}$ \\
\hline p-value & 0.482 & $<0.001$ & 0.684 & $<0.001$ & $<0.001$ \\
\hline
\end{tabular}


${ }^{\dagger}$ MI Covered and ${ }^{\ddagger}$ MI Uncovered significantly different $(\mathrm{p}<0.001)$ from all other values in same column

${ }^{\S}$ Duraphat Covered and IIDuraphat Uncovered significantly different $(\mathrm{p}<0.001)$ from all other values in same column

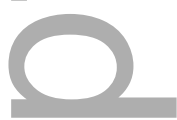

Table 3. Calcium, phosphate and fluoride ion levels in the AS after 14 days exposure to Placebo, Duraphat and MI varnish applied to one of the two demineralized lesion windows at $37^{\circ} \mathrm{C}$. The AS contained $500 \mu \mathrm{M}$ calcium and inorganic phosphate.

\begin{tabular}{|l|c|c|c|c|c|}
\hline Product & $\begin{array}{c}\text { Weight of } \\
\text { varnish } \\
(\mathbf{m g})\end{array}$ & $\mathbf{p H}$ & $\begin{array}{c}\mathbf{C a}^{+2} \\
(\boldsymbol{\mu M})\end{array}$ & $\begin{array}{c}\mathbf{P O}^{-3} \\
(\boldsymbol{\mu M})\end{array}$ & $\begin{array}{c}\mathbf{F}^{-} \\
(\boldsymbol{\mu M})\end{array}$ \\
\hline $\begin{array}{l}\text { Placebo in } \\
\text { AS }\end{array}$ & 6 & $5.26 \pm 0.03$ & $515 \pm 40$ & $545 \pm 80$ & $0.00 \pm 0.00$ \\
\hline $\begin{array}{l}\text { Duraphat } \\
\text { in AS }\end{array}$ & 6 & $5.26 \pm 0.02$ & $510 \pm 55$ & $524 \pm 39$ & $350 \pm 104$ \\
\hline $\begin{array}{l}\text { MI Varnish } \\
\text { in AS }\end{array}$ & 6 & $5.25 \pm 0.02$ & $838 \pm 175^{\dagger}$ & $846 \pm 127^{\dagger}$ & $715 \pm 253^{\dagger}$ \\
\hline
\end{tabular}

${ }^{\dagger}$ MI Varnish significantly different $(\mathrm{p}<0.001)$ from all other values in the same column

Table 4. Enamel F uptake compared with remineralization

\begin{tabular}{|l|c|c|c|}
\hline Treatment & $\begin{array}{c}\text { Measured } \mathbf{F}^{\dagger} \\
(\mathbf{w t} \%)\end{array}$ & $\begin{array}{c}\text { Predicted Mineral } \\
(\mathbf{w t} \%)\end{array}$ & $\begin{array}{c}\text { Measured Mineral } \\
\mathbf{( w t}^{\S}\end{array}$ \\
\hline Placebo covered & $0.06 \pm 0.05$ & 1.59 & 0.68 \\
\hline Duraphat covered & $0.24 \pm 0.03$ & 4.78 & 5.31 \\
\hline MI covered & $0.44 \pm 0.08$ & 10.09 & 15.61 \\
\hline
\end{tabular}

$\dagger$ Measured by EPMA (see Materials and Methods)

This article is protected by copyright. All rights reserved 
\$ Determined from measured $\mathrm{F}(\mathrm{wt} \%)$ after subtracting background $\mathrm{F}$ level assuming all mineral formed was fluoroapatite with $3.767 \%$ fluorine.

$\S$ Mineral formed by varnish treatment calculated from data in Table 2 and using the conversion of vol\%min to wt $\%$ min described by Angmar ${ }^{19}$.

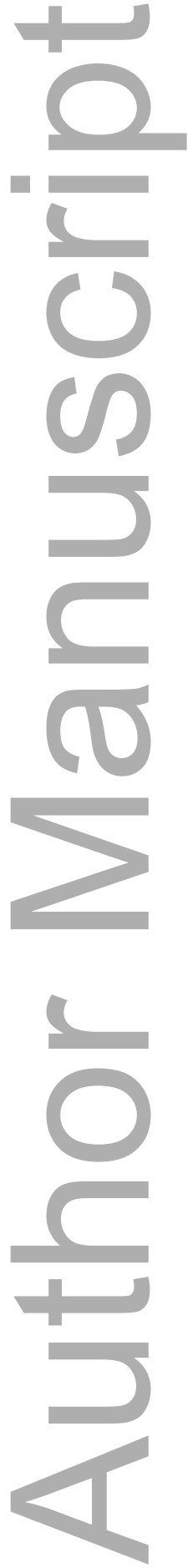




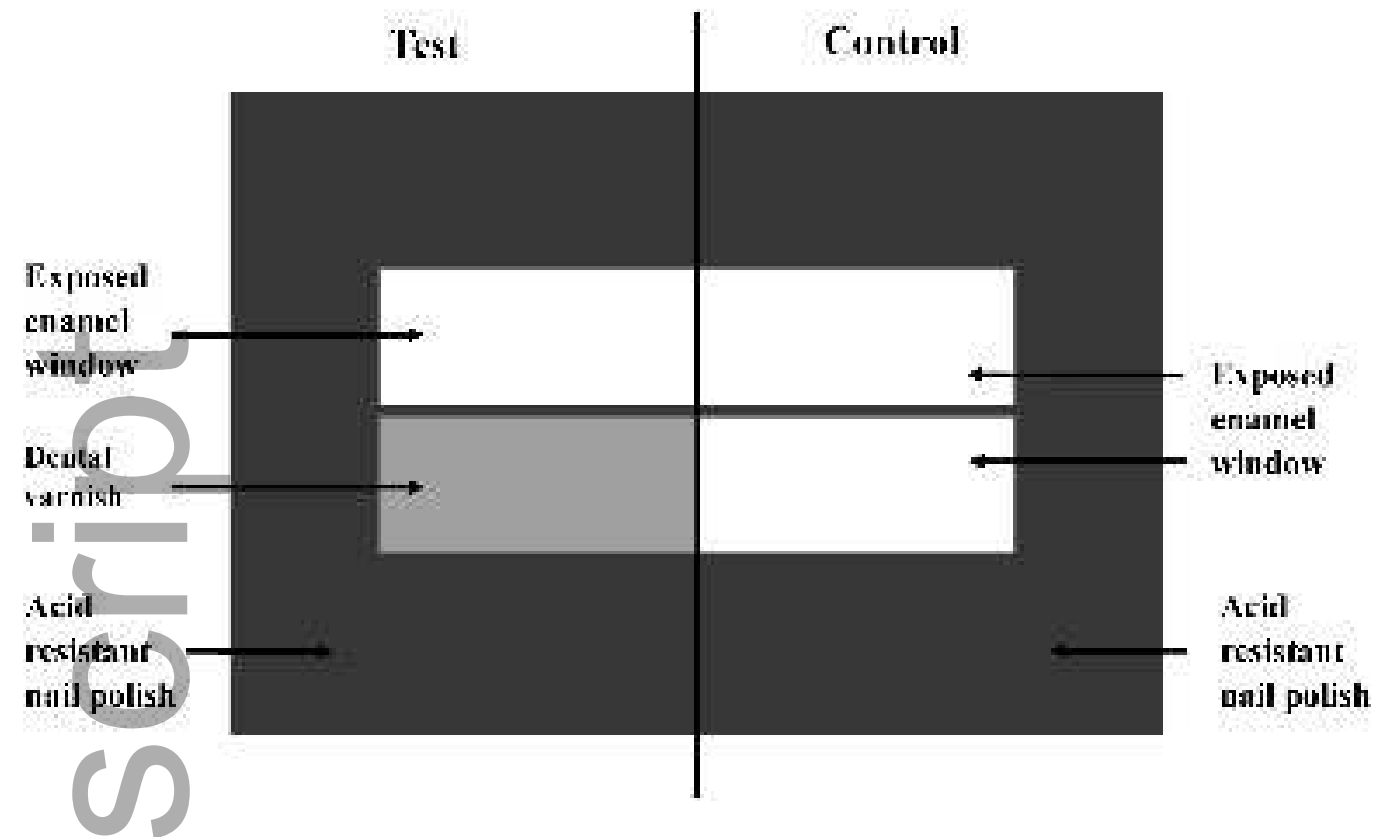

adj_12787_f1.jpg 


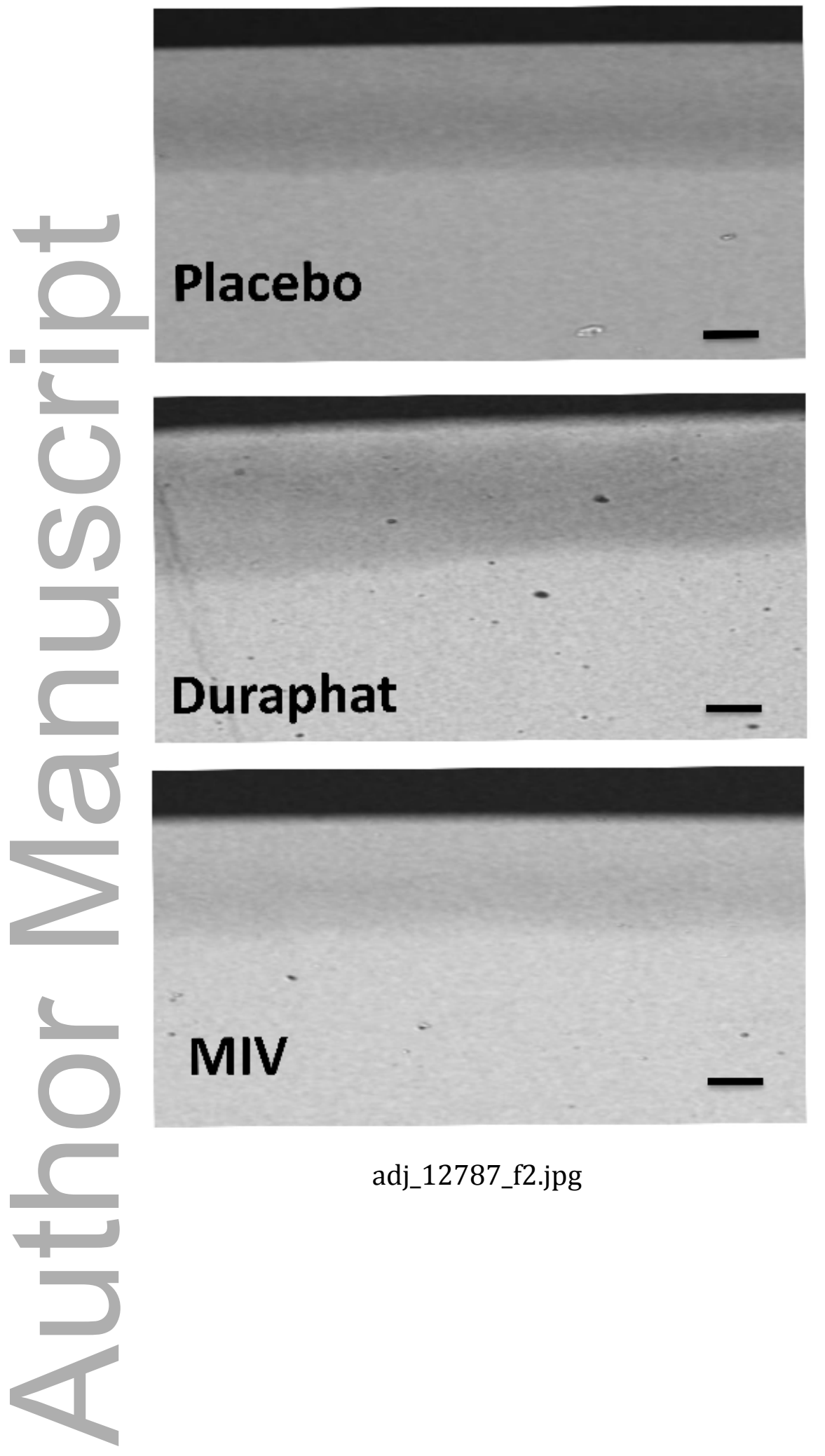

This article is protected by copyright. All rights reserved 


\section{University Library}

\section{- M M N E R VA A gateway to Melbourne's research publications}

Minerva Access is the Institutional Repository of The University of Melbourne

\section{Author/s:}

Shen, P;McKeever, A;Walker, GD;Yuan, Y;Reynolds, C;Fernando, JR;Chen, Y-Y;MacRae, CM;Schneider, P;Reynolds, EC

Title:

Remineralization and fluoride uptake of white spot lesions under dental varnishes

Date:

2020-08-05

\section{Citation:}

Shen, P., McKeever, A., Walker, G. D., Yuan, Y., Reynolds, C., Fernando, J. R., Chen, Y. Y., MacRae, C. M., Schneider, P. \& Reynolds, E. C. (2020). Remineralization and fluoride uptake of white spot lesions under dental varnishes. AUSTRALIAN DENTAL JOURNAL, 65 (4), pp.278-285. https://doi.org/10.1111/adj.12787.

Persistent Link:

http://hdl.handle.net/11343/276112 